\title{
AC motor traction drives - A status review
}

\author{
L FREDERICK $^{1}$ and GOPAL K DUBEY ${ }^{2}$ \\ ${ }^{1}$ Transportation Division, Unit III, Kirloskar Electric Co. Ltd., \\ Bangalore 560 058, India \\ ${ }^{2}$ Department of Electrical Engineering, Indian Institute of Technology, \\ Kanpur 208 016, India \\ e-mail: gdubey@iitk.ernet.in
}

\begin{abstract}
The paper presents a brief review of modern ac motor traction drives, powered from $25 \mathrm{kV}$ power frequency $a c$ supply. Drives employing voltage source inverters, current source inverters, and induction and synchronous motors have been discussed.
\end{abstract}

Keywords. Traction converters; electric traction drives.

\section{Introduction}

Owing to the advantages associated with $a c$ motors, $a c$ motor drives are fast replacing $d c$ motor drives. Modern $a c$ motor traction drives have several important features such as regenerative braking capability, very little maintenance and down-time, nearunity $p f$, nearly sinusoidal current, good adhesion, high average speed and high efficiency.

\section{Important features of electric traction drive (Dubey 1994, p. 327)}

(1) For economic reasons, a $25 \mathrm{kV}, 50 \mathrm{~Hz}$, ac traction drive employs only single-phase supply although the rating of the locomotive is as high as $6000 \mathrm{hp}$.

(2) The traction supply system is weak in nature and hence the voltage is subject to fluctuations.

(3) As traction supply is weak in nature, the reactive power has a very adverse effect. It is essential that the power factor is not allowed to be lower than 0.8 .

(4) Use of electric brakes reduces wear and tear on the track, wheels and brake shoes, thereby increasing their life substantially.

(5) Dynamic braking is generally used. But when the energy saving is large enough to justify the additional cost of the drive, regenerative braking is preferred. 
(6) Regenerative braking is generally combined with the dynamic braking.

(7) Use of the controlled rectifiers results in the generation of harmonics, which are injected into the source. This results in the following adverse effects.

(a) High frequency harmonics cause interference with the communication line.

(b) Low frequency harmonics may enter into the track circuits, leading to the maloperation of the signals.

(c) They can cause sharp fluctuations in the supply voltage.

\section{Advantages of AC motor traction drives over DC motor traction drives}

Modern traction drives generally use three-phase induction motors as traction motors. The ac motor drive has the following advantages.

(i) Three-phase induction motors are robust and have high torque-to-weight ratio.

(ii) They have simplified and reduced maintenance because of the absence of the commutator and brush gear as in $d c$ motor drives.

(iii) Full use of the available adhesion between wheel and rail is possible because of the naturally steep torque-speed characteristic of the induction motor.

(iv) Induction motors have a good regeneration capability.

(v) Due to absence of a commutator, the motor windings can be designed for higher voltages. This results in more favourable design of other components such as inverters, converters, transformer secondaries etc.

(vi) Current rating of the induction motor is low. This results in reduction of cable size, number of contactors, number of switches etc.

(vii) At the same power levels, induction motors are lighter than $d c$ motors. This results in the relatively smaller unsprung mass of the truck giving good riding characteristics and low rail stress.

(viii) Three phase induction motors have improved efficiencies and reliabilities in operation than do $d c$ motors.

(ix) With the three-phase drive, electric braking down to standstill is possible.

\section{Suitability of VSI and CSI drive for traction application (Dubey 1997)}

A three-phase $\mathrm{AC}$ induction motor should be fed from a three-phase supply capable of delivering steplessly variable frequency and voltage. The current source inverter and the voltage source inverter are available to meet this requirement. The important relative merits and demerits of CSI and VSI drives in relation to traction are as follows.

(i) CSI drives do not suffer from the shoot-through fault which is common in VSI drives.

(ii) Regenerative braking capability is inherent in CSI drives fed from a line-commutated fully controlled converter or a PWM fully controlled converter and in VSI drives 
powered from a synchronous link converter. If the $a c$ supply fails, the regenerative braking will not be possible in both the drives. Under such conditions, a VSI drive can use dynamic braking but the same is not possible with a CSI drive.

(iii) The presence of a large value inductance in the $d c$ link of a CSI drive results in the slower dynamic response compared to a PWM VSI drive. Consequently VSI drive has better adhesion (i.e. lower possibility of wheel slip).

(iv) When the source is $d c$, a PWM VSI drive will be cheaper compared to a CSI drive of the same rating. Also the requirement of the large commutation capacitors, and a large $d c$ link inductor (which is over-sized to prevent saturation), the volume and weight of a CSI drive is much higher compared to PWM VSI drive.

(v) The frequency range of the CSI is lower than that of the VSI drive. Hence the CSI drive has a lower speed range.

(vi) The CSI is not suitable for multimotor drives. Hence each motor is fed by its own inverter and rectifier. But a single diode bridge or a synchronous link converter can be used to feed a number of VSI motor systems. Alternatively a single VSI can feed a number of motors.

\section{AC motor traction drive}

\subsection{Principle of operation}

The block diagram of a popular $a c$ motor traction drive is shown in figure 1 .

The pantograph collects the power for the running locomotive from the overhead line. The pantograph is connected to the primary of the transformer. The isolation and protection devices are provided between the pantograph and transformer.

The traction transformer has a single primary winding and multiple secondary windings for feeding traction converters. The traction transformer is so designed that the percentage

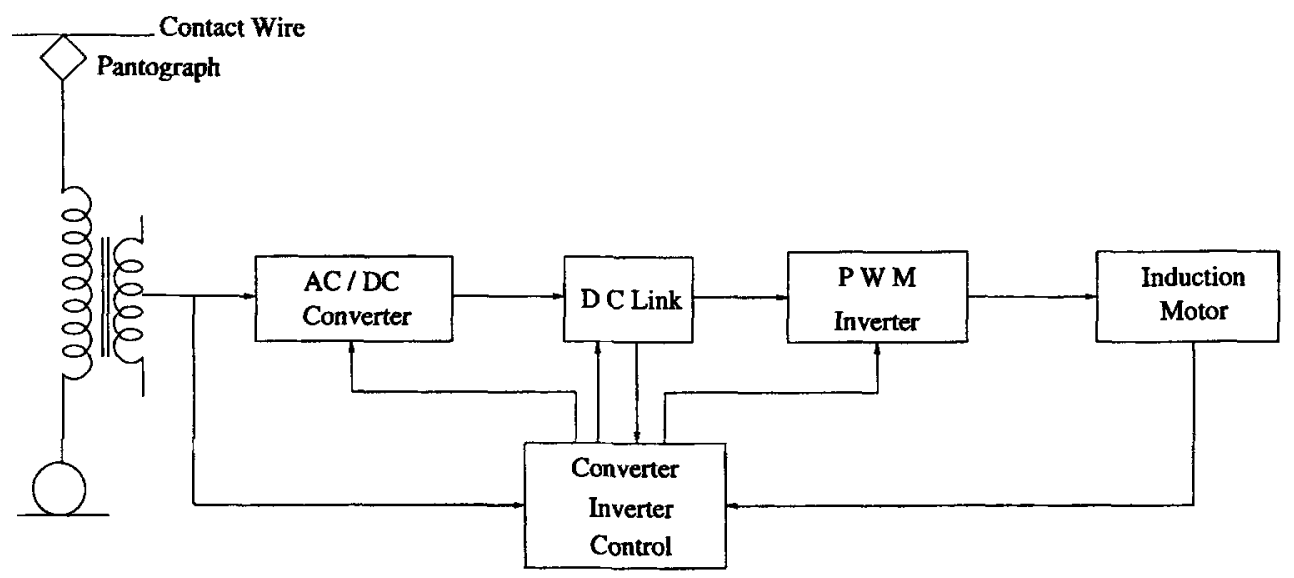

Figure 1. Block diagram of a popular ac motor traction drive. 
impedance of all the secondary windings feeding traction converters are maintained unchanged irrespective of the combined or isolated operation of the windings.

Traction power converters consist of PWM converters. These converters are connected in series or parallel. Each unit is of modular construction with built-in cooling arrangement. Converters are operated in a way so as to maintain a power factor of unity throughout the operating range, with practically zero harmonic injection into the line.

The $d c$ link consists of a suitable bank of capacitors designed to provide a stable $d c$ link voltage for feeding variable voltage variable frequency (VVVF) inverter in voltage source configuration. Alternatively $d c$ link may consist of a suitable inductor designed to provide a stable $d c$ link current for feeding CSI inverter in current source configuration.

The $d c$ link decouples the drive from the source. The inverter used may be CSI or VSI type. Generally CSI type inverter is used with synchronous motor drives and VSI type inverter is used with induction motor drives. The output of the inverter is connected to three-phase traction motors. The synchronous motors have higher full load efficiencies and power factors than induction motors. However, compared to squirrel cage induction motors they have higher cost, weight and volume for the same rating and require more maintenance.

Generally, microprocessor-based control systems are used for control of converters, $d c$ links, inverters, traction motors, braking and slip. The microprocessor also performs the task of fault diagnosis and display in addition to that of control.

\subsection{Control of three-phase ac motor traction drive}

Several drives employing squirrel cage induction motors and synchronous motors are in use for traction. Variable frequency control is used both for induction motors and synchronous motors.

Modes of operation of an induction motor traction drive are shown in figure 2 . This drive has received wide acceptance.

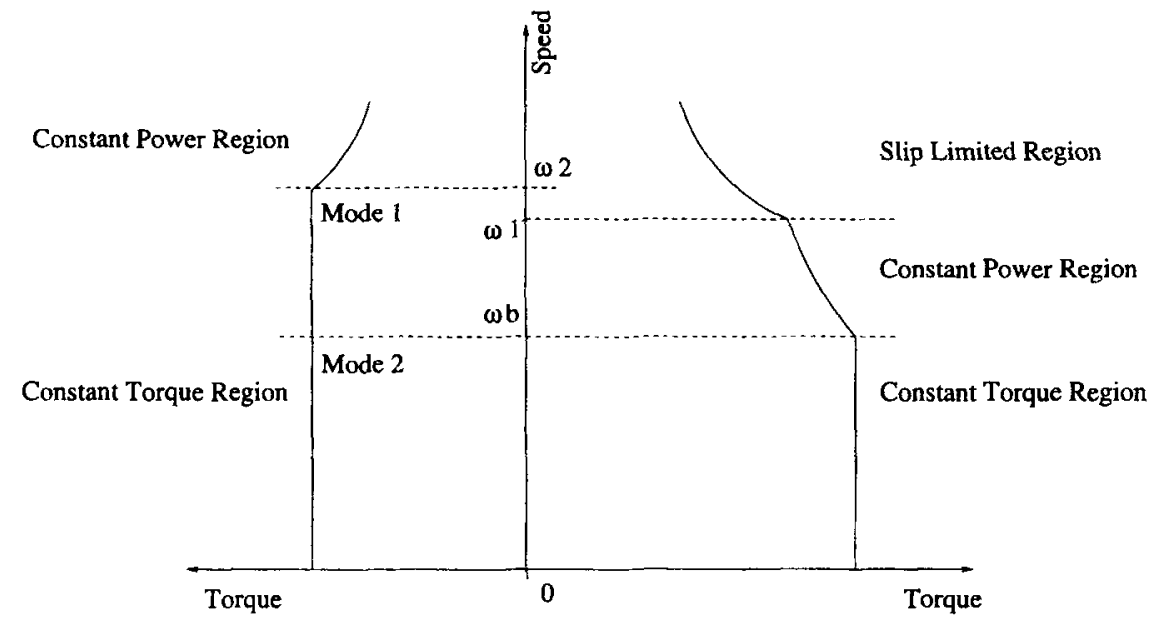

Figure 2. Modes of operation of $a c$ motors with VVVF control. 
When the drive is in the motoring region, the characteristic curve has three regions (Oldenkamp \& Peak 1985; Dubey 1989).

(i) Constant torque region;

(ii) constant power region;

(iii) slip limited region.

(i) Constant torque region: The constant torque region ranges from standstill to base speed $\left(\omega_{b}\right)$. In this region the inverter is operated to supply adjustable voltage and frequency to the motor. The motor voltage is adjusted as speed (frequency) changes to maintain a constant flux density in the motor. The motor voltage therefore increases proportionally with speed (frequency). The frequency of the voltage induced in the rotor (slip frequency) is held constant. This produces nearly constant torque and, since the power output is proportional to the speed, the power increases linearly with speed. At base speed $\left(\omega_{b}\right)$, the $a c$ voltage reaches the maximum limit of the inverter.

(ii) Constant power region: In this region, the inverter is operated to supply the adjustable frequency to the motor. The voltage is no longer adjustable and the inverter is operated at maximum voltage limit. The power output of the motor remains nearly constant. This mode of control is extended until point $\omega_{1}$, where the motor breakdown torque limit is reached.

(iii) Slip limited region: In this region, the slip frequency is maintained constant and any increase in speed is achieved by reducing the motor current. Here the motor current reduces inversely with speed and the torque decreases inversely as speed squared. This characteristic is often referred to as the series motor characteristic. The torque produced in this region is somewhat higher than that produced by a $d c$ series motor.

When the drive is in the braking region, the characteristic curve has the following regions of operation (Plunkett \& Plette 1977).

(i) Constant power region;

(ii) constant torque region.

(i) Constant power region: In this region, drive power is held constant to match the inverter maximum power capability. This mode is similar to the constant power mode during motoring and slip frequency varies in proportion to the speed (frequency).

(ii) Constant torque region: When the drive is braking, the constant torque region has two modes of operation.

(a) Model 1 - In this region, both the motor voltage and current vary approximately as the square root of speed. Hence the power varies directly with speed, as the slip frequency is 
Table 1. Enforced limits, for psophometric currents.

\begin{tabular}{ll}
\hline Particular & \multicolumn{1}{c}{ Enforced limits } \\
\hline Psophometric current & $\leq 10 \mathrm{~A}$ \\
DC component of current & $\leq 4.7 \mathrm{~A}$ \\
Second harmonic current & $\leq 8.7 \mathrm{~A}$ \\
Audio frequency component & \\
$1650-1750 \mathrm{~Hz}$ & \\
$1950-2050 \mathrm{~Hz}$ & $\leq 400 \mathrm{~mA}$ amplitude \\
$2250-2350 \mathrm{~Hz}$ & \\
$2550-2650 \mathrm{~Hz}$ & $\leq 270 \mathrm{~mA}$ amplitude \\
High frequency component & \\
$5050-5100 \mathrm{~Hz}$ & \\
\hline
\end{tabular}

varied in direct proportion to the speed. The power fed back to the source is proportional to the speed, decreasing linearly with speed.

(b) Mode 2 - In this region, the motor current is held constant as slip frequency is held constant. Motor voltage is adjusted as speed (frequency) falls to maintain a constant flux density in the motor. Motor voltage therefore reduces proportionally with speed (frequency). At very low speeds the electric braking is allowed to fade.

\subsection{Requirements of ac motor traction drives}

(i) The source side converter should ensure a power factor as near unity as possible.

(ii) The converter should be designed such that the psophometric disturbance current is kept within an enforced limit (table 1).

(iii) The converter should be designed such that no intolerable level of interference is caused to track circuit, signal or telecommunication equipment.

(iv) The power converter/inverter should ensure four-quadrant operation, and regenerative braking should be available from maximum speed range up to standstill.

(v) The power converter/inverter should ensure the full utilization of the available adhesion.

(vii) The inverter should incorporate beatless control system to suppress beat phenomenon.

\section{Load-commutated inverter synchronous motor traction drives}

\subsection{Basic principle (Dubey 1989, p. 416)}

Generally a self-controlled synchronous motor drive is used for electric traction drives. Figure 3 shows a simple load-commutated inverter synchronous motor drive. The drive employs two converters termed as source-side and load-side converters. Source-side and load-side converters are both operated in first and fourth quadrants. Hence, regenerative braking capability is inherent. 


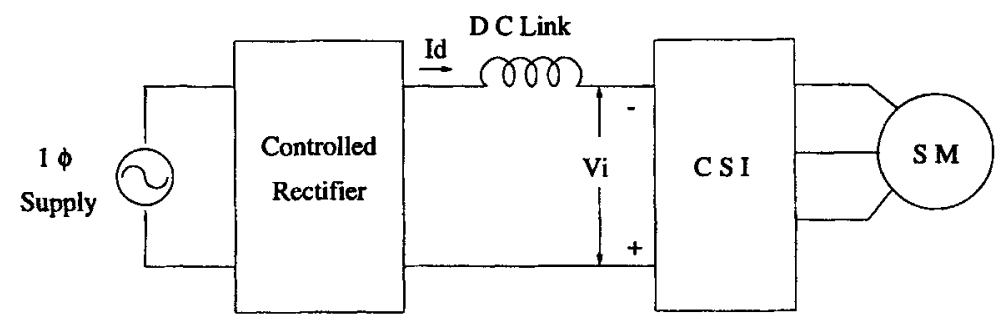

Figure 3. Load-commutated inverter synchronous motor drive.

In a self-controlled synchronous motor drive, the following control strategies are generally used.

(i) Constant margin angle control;

(ii) constant lead angle control;

(iii) constant no-load angle control.

In all the above control strategies, the synchronous motor operates with a leading power factor and the thyristors of load-side converters are commutated by the motor-induced voltages, in the same way as the thyristors of line-commutated converters. Because the firing is synchronized with the machine-induced voltage, the machine always operates in self-control mode. The supply to source side converters may be $d c$ or $a c$.

A load-commutated inverter synchronous motor traction drive using thyristors is shown in figure 4 . Here the supply is $d c$. The $d c$ current source is formed by a two-quadrant chopper (quadrants I \& VI), a $d c$ link inductor and a current feedback. The load-side converter is commutated by the back emf of the synchronous machine (Pearson $\&$ Sen 1984).

When the overhead catenary is $a c$, the scheme shown in figure 5 is used. Here the current source is formed by source side converter (a controlled rectifier), $d c$ link inductor

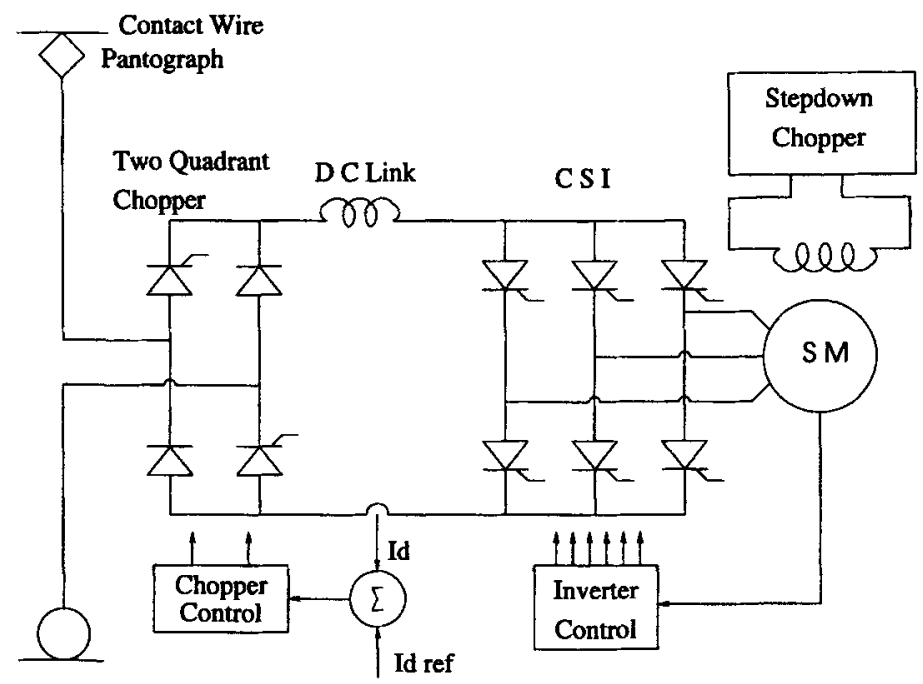

Figure 4. Regenerative synchronous motor $d c$ traction drive. 


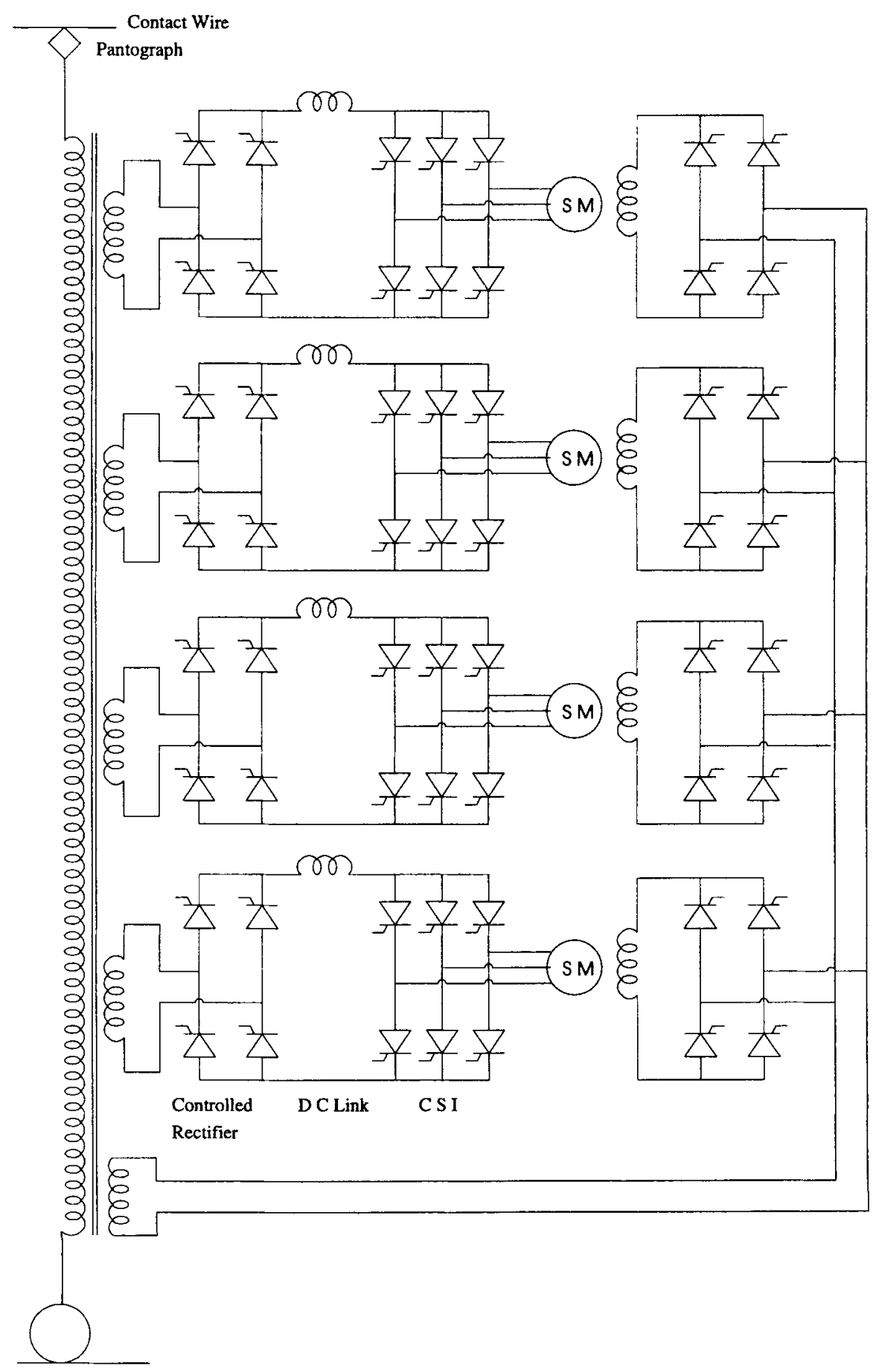

Figure 5. Regenerative synchronous motor $a c$ traction drive. 


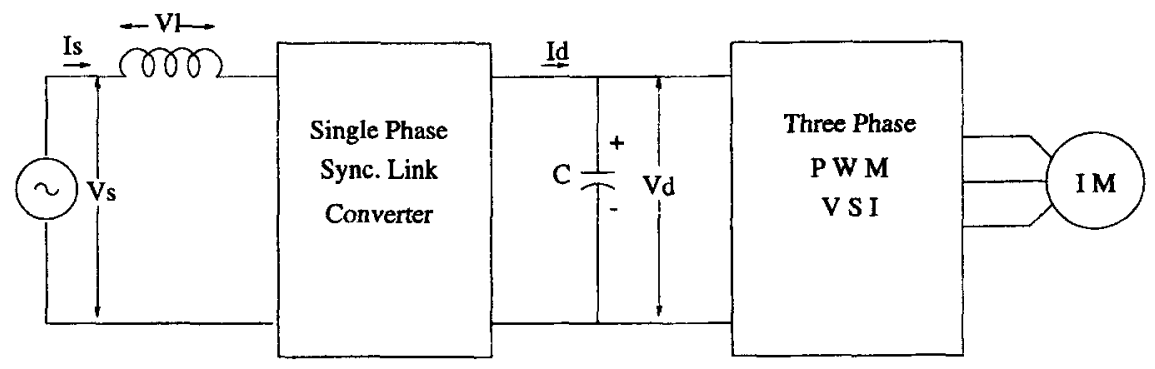

Figure 6. Regenerative induction motor drive using synchronous link converter.

and the current loop. The load-side converter is operated in self-control mode and with load commutation.

\subsection{Control of load commutated inverter synchronous motor drive}

When the drive is in motoring, the source-side converter acts as a rectifier and the load-side converter acts as an inverter, resulting in the forward motoring operation. In this mode of operation the average value of $V_{i}$ (figure 3 ) is negative, and $I_{d}$ is positive and hence the power flows from the $d c$ link to the machine giving operation in quadrant $\mathrm{I}$.

For braking the drive, the load side converter is controlled such that the average $V_{i}$ is positive. Since the direction of $I_{d}$ remains unchanged, the power flows from the motor to the $d c$ link. In this mode of operation, the load-side converter works as a rectifier and the machine regenerates. The source-side converter is operated to feed the energy back to the source.

For reversing the direction of the drive, the phase sequence of the load-side converter is reversed by interchanging the control signals between switches of any two legs of the inverter.

In the case of the load-commutated synchronous motor drive, at low speeds the induced emf will be insufficient to commutate the thyristors of the load-side converter. Therefore, at start and for speeds below $10 \%$ of base speed, the commutation of the load-side converter thyristor is done by forcing the current of conducting thyristors to zero, with the help of the source-side converter (Peterson \& Frank 1972).

Alternatively, a synchronous motor can be started by employing a simple forcedcommutation circuit utilizing a single commutation capacitor and two auxiliary thyristors for the entire inverter (Steigerwald \& Lipo 1979).

\section{VSI-squirrel cage induction motor drive}

\subsection{Basic principle}

A regenerative induction motor drive using a synchronous link converter is shown in figure 6. The synchronous link converter permits the realization of an economic regenerative ac drive with a power factor of nearly unity and a low harmonic current in the source current. The converter circuit is shown in figure 7. 


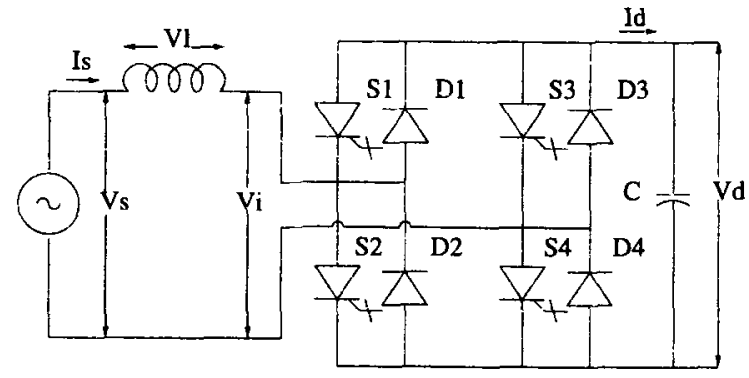

Figure 7. Single phase synchronous link converter.

When the single-phase voltage source inverter is operated with pulse-width modulation, it produces the voltage $\bar{V}_{i}$. If the voltage $V_{d}$ is maintained constant, the magnitude of $V_{i}$ may be varied by adjustment of the modulation index of the converters. The phase of $\bar{V}_{i}$ w.r.t. $\bar{V}_{s}$ can be altered by changing the phase of firing pulses of the inverter, w.r.t. the phase of $\bar{V}_{s}$. By appropriately choosing the magnitude and phase of $\bar{V}_{i}$ for a given $\bar{I}_{s}$, the phase angle between $\bar{V}_{s}$ and $\bar{I}_{s}$ can be adjusted to a desired value.

Figure 8 shows the phasor relationship of various vectors when the phase angles between the source voltage $\bar{V}_{s}$ and source current $\bar{I}_{s}$ are $0^{\circ}$ and $180^{\circ}$ respectively. In either case the power factor is unity. When the phase angle is zero, the converter works as a rectifier transferring power from $a c$ source to the $d c$ link. In this mode of operation, current $I_{d}$ has a positive direction. When the phase angle is $180^{\circ}$ current $I_{d}$ reverses and the power flows from the $d c$ link to the source and the converter works as an inverter. Because of the operation of the converter with pulsewidth modulation, the source current has a low harmonic content.

Figure 9 shows a three-phase regenerative traction drive using a synchronous link converter and PWM inverter. Here two synchronous link converters are connected in parallel feeding an inverter, which in turn feeds three induction motors connected in parallel. Two such units are fed from a common transformer.

Depending upon the power level IGBTs/GTOs can be used in the construction of a synchronous link converter. In case of Electrical Multiple Units (EMU), IGBTs can be used both in synchronous link converter and inverter. Since the IGBTs can be operated at a frequency of $2.5 \mathrm{kHz}$ the harmonics in the source current can be reduced to a smaller value. We can use sinusoidal PWM, current controlled PWM or vector PWM for both converter and inverter. In case of a locomotive, because of the large power levels, GTOs have to be used. Since at high power levels, GTOs are operated around $400 \mathrm{~Hz}$, generally sinusoidal PWM is used and more than one converter is operated in parallel to keep the harmonics in the source current within acceptable limits.

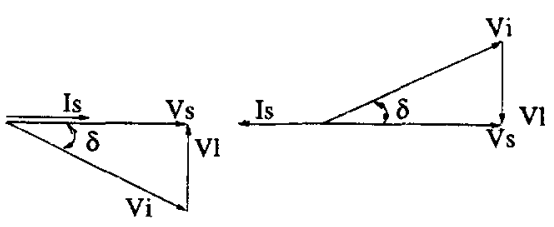

Figure 8. Phasor diagram of synchronous link converter. 


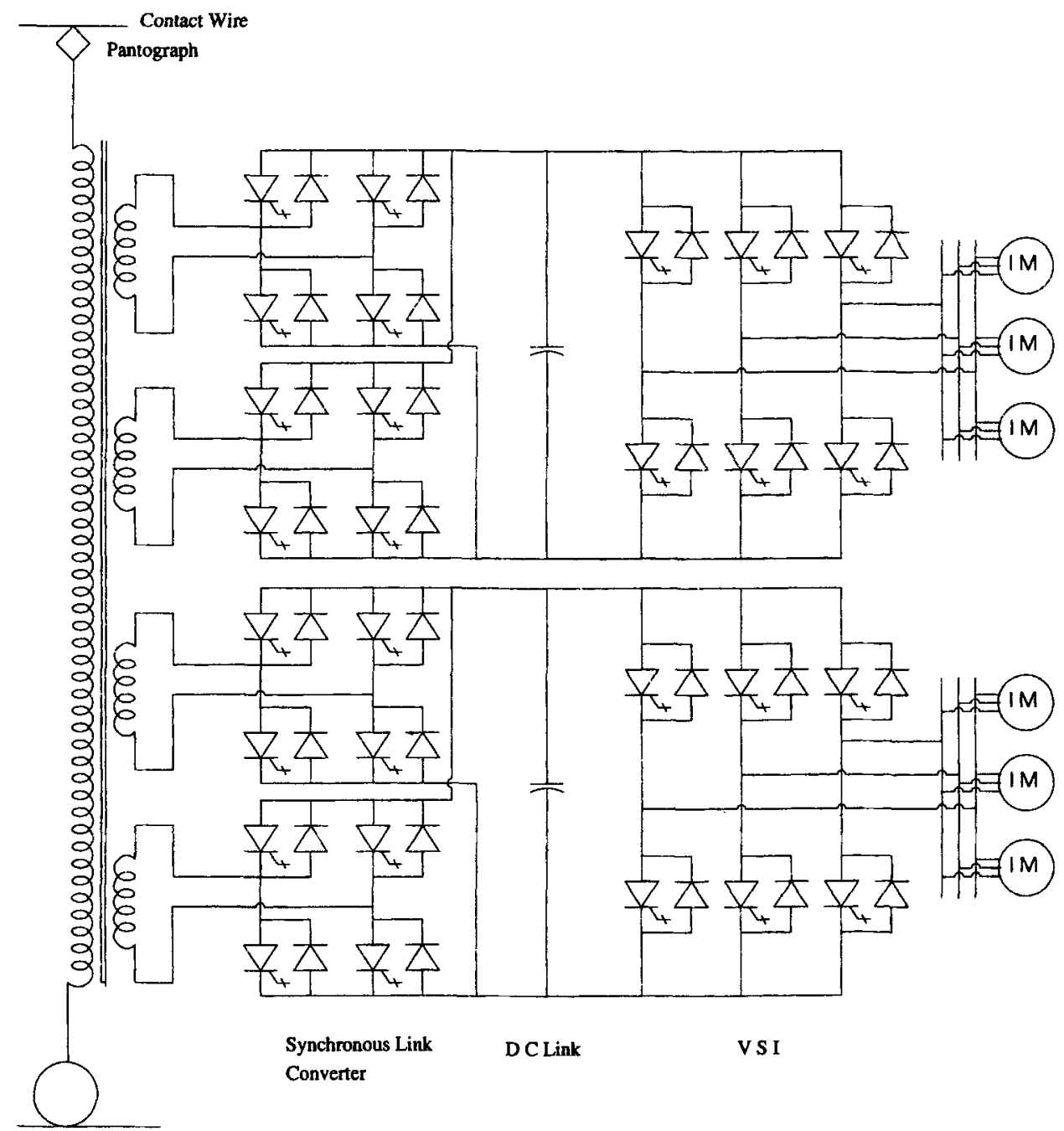

Figure 9. Regenerative traction drive using synchronous link converter and PWM VSI.

\subsection{Control of VSI - Squirrel-cage induction motor traction drive}

The modern VSI squirrel-cage induction motor traction drives are generally torquecontrolled drives. The drive is started with reduced voltage and frequency. This frequency reduction improves the motor power factor and increases the torque per ampere at the start. Hence the rated torque is available at the start, and the drive is accelerated to its operating speed. The drive is operated as described in $\S 5$.2. Here the power is transferred from the source to the load.

For transferring the operation from motoring to regenerative braking, the inverter frequency is reduced. A reduction of inverter frequency makes the synchronous speed less than the motor speed and transfers operation from quadrant I to quadrant II. Here the power flows from motor to $d c$ link and from $d c$ link back to source. The inverter voltage and frequency are reduced to brake the machine to zero speed. 


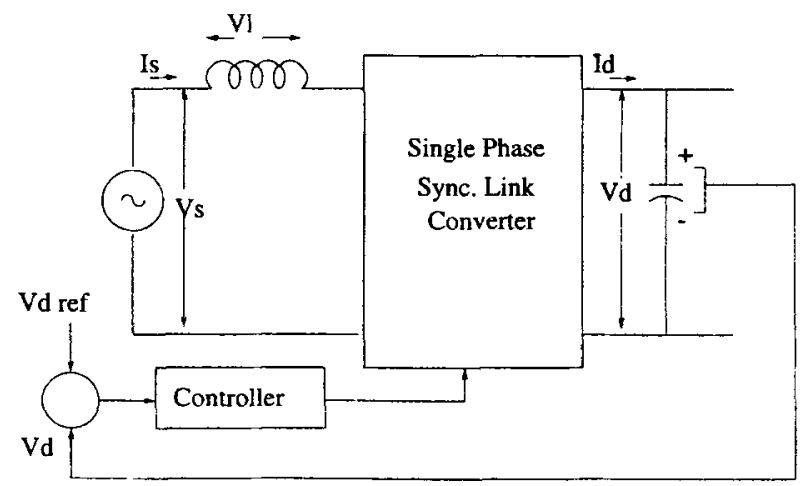

Figure 10. Closed loop control around a synchronous link converter.

For speed reversal, the phase sequence of the inverter voltage is reversed by interchanging the control signals between the switches of any two legs of the inverter. In the scheme described above, when the source is unable to take back the regenerated power, a dynamic braking scheme can be used.

For this a braking resistor is connected in series with a switch across the $d c$ link capacitor ' $C$ '. The generated power charges the filter capacitor and its voltage rises. When the filter capacitor voltage reaches a prescribed maximum value, the switch is turned on, connecting the braking resistor across the capacitor. The energy generated and the energy supplied by the filter capacitor are dissipated in the braking resistor. The capacitor voltage falls. When the capacitor voltage reaches a prescribed minimum value the switch is turned off. Again the capacitor voltage starts rising and the cycle repeats. Thus only that portion of the regenerated energy is dissipated by dynamic braking which cannot be accepted by the source.

The following control techniques are generally used with synchronous link converter.

(1) Current-controlled PWM;

(2) Indirect current control (sinusoidal pulsewidth modulation and its modifications).

With the above mentioned current controlled techniques, for a given value of reference, the power input to the converter has a fixed value. When the load on the converter is decreased, there is imbalance between the power input and the power output. Hence a closed loop voltage control is provided across the synchronous link converter as shown in figure 10.

\section{Harmonic reduction and control of torque pulsation}

The line side converter generates current harmonics which are injected into the overhead lines. Hence, measures are taken to keep the harmonics below a desired limit. Some of the methods used with VSI squirrel cage induction motor drive are as below.

(i) By using series/parallel connection of converters, the supply current harmonics can be reduced considerably. If $N$ converters are put in series/parallel and if the carrier signals of individual converters are equally displaced by an angle $\pi / N$, then some of the reflected harmonics cancel on the primary side of the transformer. The ripple 


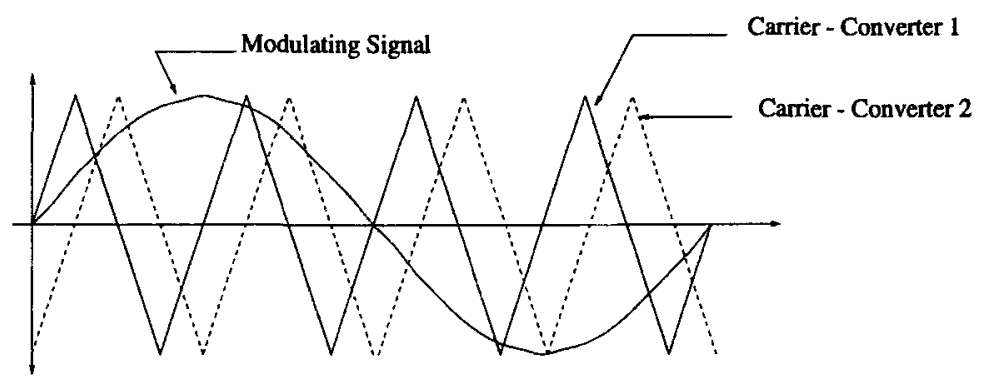

Figure 11. Carrier signals for two converters operating in parallel.

frequency of the primary current has a frequency $(N \times f c)$, where $N$ is the number of converter put in parallel/series and $f c$ is the carrier signal frequency.

For example, if the synchronous link converter is realized by using two GTO converters, say converter I and converter II in parallel, then the firing of the GTOs in converter I and converter II is done by using a common modulating signal and the triangular carrier wave phase shifted from each by an angle $90^{\circ}$ (because $N=2$ ) as shown in figure 11.

(ii) By using three-level converters as compared to two-level converters.

(iii) By employing switched electronic compensator which generates an exact replica of the harmonic current. It is fed into an extra winding of traction transformer to produce harmonic counter emf. This ensures that the transformer main flux is sinusoidal, and hence so is the induced voltage in the primary. The line current is low-pass filtered by the transformer leakage inductance and assumes a sinusoidal waveform.

For reducing the harmonics in the inverter output voltage and hence to minimize the torque pulsations, the inverters can be connected in parallel. They share the common $d c$ link and the ac output terminals of the respective phases are connected through an interphase reactor. The mid-point of the inter-phase reactor is connected to the respective phases of an induction motor. The inverters are operated with common modulating signals, but with the carrier signals of individual inverters being equally displaced within the carrier period interval.

\section{Advantages of VSI squirrel-cage induction motor traction drive}

The VSI squirrel-cage induction motor traction drive has the following advantages.

(i) Power factor of unity.

(ii) Low harmonic content in the source current.

(iii) Regenerative braking capability at low cost.

(iv) Smooth acceleration due to absence of low speed torque pulsations.

(v) Efficient and quiet operation due to low harmonic content in the motor input voltage.

(vi) Good adhesion due to fast dynamic response and absence of torque pulsations.

(vii) Multimotor drive possible due to use of VSI. 
(viii) Regenerative braking capability offering energy saving.

(ix) Dynamic braking can be resorted in the event of catenary failure due to use of VSI.

(x) Improved energy efficiency.

(xi) Reduced maintenance cost.

(xii) Reduction in the size and weight of traction circuit equipment.

(xiii) Possibility of reducing the capacity of the traction substation, because the power factor of the system is always unity, both in powering and braking.

\section{Conclusions}

AC motor traction drives are superior to DC motor traction drives. Because of recent advances in power electronics, drive control techniques and availability of micro-controllers for control and fault diagnosis have enabled the realization of traction drives with high efficiencies, high levels of performance and low down-times.

\section{References}

Dubey G K 1989 Power semiconductor controlled drives (Englewood Cliffs, NJ: Prentice Hall) Dubey G K 1993a Semiconductor controlled AC motor traction drives. Course Package, Continuing Education Program of Indian Society for Technical Education

Dubey G K 1993b Semiconductor controlled DC motor traction drives. Course Package, Continuing Education Program of Indian Society for Technical Education

Dubey G K 1994 Fundamentals of electric drives (New Delhi: Narosa)

Dubey G K 1997 A modern $25 \mathrm{kV}$ squirrel cage induction motor drive for traction. National Conference on Electric Drives and Control for Transport Systems, Vidisha

Dubey G K, Rao K C (eds) 1993 Power electronics and drives (New Delhi: Tata McGraw-Hill) vol. 1

Dubey G K, Doradla S R, Joshi A, Sinha R M K 1986 Thyristorised power controllers (New Delhi: Wiley Eastern)

Holtz J, Onnokrah J 1992 Adaptive optimal pulsewidth modulation for the line side converter of electric locomotive. IEEE Trans. Power Electron. PE-7: 205-211

Kanetkar V R, Dubey G K 1995 Bidirectional AC to DC power conversion - Trends, developments and application of concern. Indian Elec. Eng. Manuf. Assoc. J.: 7-28

Kielgas H, Nill R 1980 Converter propulsion system with three-phase induction motors for electric traction vehicle. IEEE Trans. Ind. Appl. 16: 222-223

Kliman G B 1972 Harmonic effects in pulsewidth modulated inverter induction motor drive. IEEE Ind. Appl. Soc. Annu. Meeting pp 783-790

Lienau W, Muller Hellman A, Skudelny H C 1980 Power converters feeding asynchronous traction motors of single phase AC vehicles. IEEE Trans. Ind. Appl. 16: 103-110

Nakamura K, Kimura A, Iwataki M 1988 Inverter drive system for AC electric rolling stock. Hitachi Rev. 37: 71-376

Oldenkamp J L, Peak S C 1985 Selection and design of inverter driven induction motor for traction drive system. IEEE Trans. Ind. Appl. 21: 259-265

Onnokrah J, Holtz J 1995 Total compensation of line side switching harmonics in converter fed AC locomotive. IEEE Trans. Ind. Appl. 31: 1264-1273 
Pearson, Sen P C 1984 Brushless DC motor propulsion using synchronous motors for transit systems. IEEE Trans. Ind. Electron. IE-31: 346-351

Peterson T, Frank K 1972 Starting of large synchronous motor using static frequency converter. IEEE Power Appl. Syst. 91: 172-179

Plunkett B, Plette D I 1977 Inverter induction motor drive for transit car. IEEE Trans. Ind. Appl. 13: $26-37$

Robertson S D T, Hebbar K M 1971 Torque pulsation in induction motor with inverter drivers. IEEE Trans. Ind. General Appl. 7: 318-323

Steigerwald R L, Lipo T A 1979 Analysis of a novel forced commutation starting scheme for a load commutated synchronous motor drive. IEEE Trans. Ind. Appl. IA-15: 14-24

Sukegawa T, Kamiyama K, Takahashi J, Kimi, Matsutake M 1992 A multiple PWM GTO line side converter for unity power factor and reduced harmonics. IEEE Trans. Ind. Appl. IA-28: 1302-1308

Yasunami M, Nakamura K, Sakane T 1986 Application of power electronics to rolling stock. Hitachi Rev. 6: 305-310 